\title{
Chemically-amplified backbone scission (CABS) resist for EUV lithography
}

\author{
Theodoros Manouras, Dimitrios Kazazis, and Yasin Ekinci \\ Paul Scherrer Institut, 5232 Villigen, Switzerland \\ E-mail: tmanouras@gmail.com
}

\begin{abstract}
Polymeric materials with an imaging chemistry based on the main chain cleavage under the influence of photogenerated acid are a promising resist platform for EUV lithography. Backbone scission resist materials are, in principle, capable of creating very small structures due to the fact that the removing parts can have dimensions in the order of the monomers that they consist of. Nevertheless, in the case of the commonly used non-chemically amplified materials of this type, issues like sensitivity and poor etch resistance limit their applications, whereas inadequate etch resistance and non-satisfactory process reliability are the usual problems encountered in acid-catalyzed materials based on main chain scission. In this work, we report on optimization of the formulation of new high-sensitive polymeric materials for EUV lithography by tuning the ratio between the photoacid generator (PAG) and the base quencher. In our material design, the acid-catalyzed chain cleavable polymers contain very sensitive acid-labile bonds in their backbone while they remain intact in alkaline ambient. These photoresists were evaluated with several PAG and base quencher (BQ) loadings. The PAG ratio spans from $4 \%$ to $7 \%$ with respect to polymer weights, whereas the BQ ratio tuned to $5 \%, 10 \%$, and $15 \%$ with respect to PAG weight. High-performance patterning capabilities were achieved for lines\spaces down to $22 \mathrm{~nm}$ half-pitch using EUV interference lithography. We report linewidth roughness versus dose-to-size for $25 \mathrm{~nm}$ and $22 \mathrm{~nm}$ half-pitch for different PAG and BQ loadings and provide a comparison.
\end{abstract}

Keywords: EUV lithography, Photoresist, Chemical amplified photoresists, Backbone scission

\section{INTRODUCTION}

Extreme ultraviolet lithography (EUVL) with exposure at $13.5 \mathrm{~nm}$ wavelength has been recently adopted by the semiconductor industry as the leading-edge lithography technology to fulfill the need for decreasing device critical dimensions (CD) at sizes below the $20 \mathrm{~nm}$ resolution. The transition from $193 \mathrm{~nm}$ to $13.5 \mathrm{~nm}$ has emerged dramatic challenges in resist materials design due to different mechanisms of the initiation of a chemical reaction. In traditional photolithography, i.e., $193 \mathrm{~nm}$, a photon promotes an electron from bonding to an anti-bonding orbital, resulting in the desired photoreaction. In the case of photoacid generators (PAGs), the absorption of a photon leads to the direct decomposition of the PAG molecule generating an acid molecule. In contrast, EUV photons have sufficient energy to ionize the resist molecules, and the producing photoelectrons initiate chain events leading to acid production. In this direction, both fundamental studies on the radiation-induced chemistry at this wavelength range and a plethora of new ideas targeting the design of new highly sensitive and top-performing resists have been proposed [1]. Besides the traditional areas of acid-catalyzed chemically amplified resists and the resists based on polymer backbone scission, new ideas have been proposed based on the insertion of metal compounds or compounds of other highly absorbing elements in the resist formulations [2]. EUV lithography requires high-performance photoresists with high sensitivity $\left(<20 \mathrm{~mJ} / \mathrm{cm}^{2}\right)$ to secure high scanner throughput in the high-volume manufacturing environment. The well-known tradeoff in optimizing sensitivity, roughness, and resolution continues to pose huge challenges towards high NA EUVL. Until now, chemicallyamplified resists (CARs) have been mainly used in EUVL since they have the advantage of compatibility with mature manufacturing. However, issues such as relatively low sensitivity, photon shot noise, and LWR make these to be still far from manufacturing requirements for tighter CDs. On the other hand, metal-containing resists have attracted a lot of attention in recent years.[3] The metal oxide resists still need improvements in sensitivity, while nanoparticles cause severe resolution and roughness problems. Thus, although metal-containing resists utilize novel patterning mechanisms and smaller building blocks, the RLS tradeoff is still hindering performance. In addition, due to the relatively short history of the metal resists, their integration into high-volume manufacturing requires tedious efforts in resist material optimization and risk management [4-6].

Extreme Ultraviolet (EUV) Lithography XII, edited by Nelson M. Felix,

Anna Lio, Proc. of SPIE Vol. 11609, 116090H - @ 2021 SPIE

CCC code: $0277-786 X / 21 / \$ 21 \cdot$ doi: $10.1117 / 12.2584085$

Proc. of SPIE Vol. $11609116090 \mathrm{H}-1$ 
During the last decade, several approaches in CARs have been proposed to overcome the RLS tradeoff. Flood exposure-assisted chemical gradient enhancement technology (FACET) has been introduced to improve the resolution, process control, roughness, patterning failure, and sensitivity.[7] This concept is based on the increase in UV absorption after the influence of the EUV-generated acid.[8] After that, the UV flood exposure induces acid production in these areas. In another approach, acid amplifiers (AAs) were used in EUV photoresist to increase the acid production [9]. AA is a compound that decomposed rapidly after the influence of an acid to generate additional acid molecules. These compounds can be used in ordinary environmentally stable chemically amplified photoresist (ESCAP) photoresists, improving resolution, LER, and sensitivity [10]. In addition, new chemical amplification processes have been proposed, such as a multi-trigger concept. In a multi-trigger material, a catalytic process is utilized following the resist exposure in a similar manner to a chemical amplified photoresist. However, in multi-trigger resist, multiple photoacids activate multiple acidsensitive molecules, which then react with each other to cause a single resist event [11-14]. On the other hand, backbone scission materials could, in principle, be capable of creating very small structures to the dimensions of the monomers they consist of. Polymethyl methacrylate and other methacrylic polymers (ZEP) have been widely used as e-beam resist, showing capabilities for structures below $10 \mathrm{~nm}$ half-pitch (HP) $[15,16]$. Furthermore, in our previous studies using chemical amplified backbone scission resist, we demonstrated the high sensitivity shown in EUV as well as the ability to create very small structures (20 nm HP) [17].

In this study, we evaluated different resist formulations having several PAG and BQ loadings. More specifically, the resist formulations contained 4\%, 5\%, 6\%, and 7\% PAG with respect to polymer weight and 5\%, 10\%, and 15\% BQ with respect to PAG weight. The imaging chemistry is based on the main chain scission mechanism of polymeric materials, which show high sensitivity in EUV and the ability to create high-resolution patterns. In our case, we have designed a CAR in which the imaging chemistry depends on the acid-catalyzed scission of the polymeric backbone. The chemical structure of the polymers was designed to enhance the etch resistance of the photoresist and to tune the $\mathrm{Tg}$ of the polymer into acceptable values for lithographic applications. In this paper, we present the results from the different PAG/BQ ratios plotted as LWR versus dose-to-size for $25 \mathrm{~nm}$ and $22 \mathrm{~nm}$ HPs.

\section{METHODS}

\subsection{Materials and their synthesis and characterization}

All solvents and reagents were purchased from Sigma or Alfa Aesar and were of analytical or HPLC grade. Tetrahydrofuran (THF) was distilled three times from potassium. The monomers were passed over a column of basic alumina to remove the inhibitors and protonic impurities.

Polymer synthesis was carried out by acid-catalyzed stepwise addition of the monomers. Predetermined amounts of the monomers were dissolved in anhydrous tetrahydrofuran in a concentration of $1.0 \mathrm{M}$. A catalytic amount was then added, and the solution was stirred at room temperature. After $24 \mathrm{~h}$, the polymerization reactions were stopped with triethylamine, and subsequently, the polymers were precipitated into cold hexanes. The solid was then dried in vacuo overnight. Gel permeation chromatography was carried out using a Waters system equipped with an ultraviolet and refractive index detector and mixed $\mathrm{D}$ and $\mathrm{E}$ columns. The molecular weights and the molecular weight distributions of the polymers were determined using PS standards with THF as an eluent at $40{ }^{\circ} \mathrm{C}$ and a flow rate of $1 \mathrm{ml} \mathrm{min}{ }^{-1}$. NMR studies were carried out with a Bruker Advance DPX 300 NMR Spectrometer (300 MHz). Thermogravimetric analysis was performed using a Perkin Elmer pyris diamond TG/DTA instrument with a heating rate of $10{ }^{\circ} \mathrm{C} / \mathrm{min}$ under dry nitrogen atmosphere. Glass transition temperatures were measured on a Perkin Elmer diamond DSC instrument using repeated heat/cool cycles at 10 ${ }^{\circ} \mathrm{C} / \mathrm{min}$ between -50 and $150{ }^{\circ} \mathrm{C}$.

\subsection{Preparation of the resists and their lithographic evaluation}

$\mathrm{Si}(100)$ wafers were primed using HMDS. The wafers were dehydrated at $180{ }^{\circ} \mathrm{C}$ for 1 hour, followed by spin-coating of HMDS at $5000 \mathrm{rpm}$ for 1 minute. The spin-coated wafers were cured at $120^{\circ} \mathrm{C}$ for 15 minutes. The polymer was dissolved in propylene glycol methyl ether acetate at room temperature to yield $1-3 \mathrm{wt} \%$ polymer solutions. Then, the photoacid generator Triphenylsulfonium triflate or N-Hydroxynaphthalimide triflate was added to the solution at concentrations of 4-7 wt \% with respect to the polymer followed by the addition of aminoanthracene at concentrations of 5-15\% with respect to the photoacid generator weight. Photoresist thin films were fabricated by spin-coating a photoresist solution at $2000 \mathrm{rpm}$ 
for 60 seconds. Prior to spin coating, the silicon substrates were primed 2 times by spin-casting propylene glycol methyl ether acetate $\left(4000 \mathrm{rpm}, 60\right.$ seconds). After spin-coating, the photoresist thin films were baked for $2 \mathrm{~min}$ at $100{ }^{\circ} \mathrm{C}$ on a hotplate to remove any residual propylene glycol methyl ether acetate. The film thickness was determined by profilometer (Veeco Dektak 150). SEM images were obtained using a Hitachi Regulus 8230 FESEM at 500 eV. FTIR spectra (resolution $4 \mathrm{~cm}-1$ ) were recorded using a Bruker Tensor Fourier Transform IR spectrometer. Optical lithography at EUV wavelength was carried out at the XIL-II beamline of the Swiss Light Source.[18] Films were then post-exposure baked (PEB) at $60{ }^{\circ} \mathrm{C}$ for 2 minutes, and were developed using aqueous $0.26 \mathrm{~N}$ tetramethylammonium hydroxide (TMAH) solution for $60 \mathrm{~s}$. Oxygen plasma etch resistance experiments were carried out in a reactive ion etcher NE330 tool.

\section{RESULTS AND DISCUSSION}

\subsection{Polymeric material design, synthesis and characterization}

Figure 1 shows the structure of the designed random copolymers synthesized by polycondensation reactions. The monomers were selected with the aim of improving the specific properties of the final random copolymers. Random copolymers consisted of about $70 \%$ of the monomer R1, about $20 \%$ of the monomer R 2 and about $10 \%$ of the monomer R3. Monomer R1 and R2 give properties such as glass transition temperature control, improved surface adhesion, solubility, etch resistance, and compatibility with other substances. Monomer R3 was selected to improve the compatibility between the random copolymer, the photoacid generator and the base quencher.

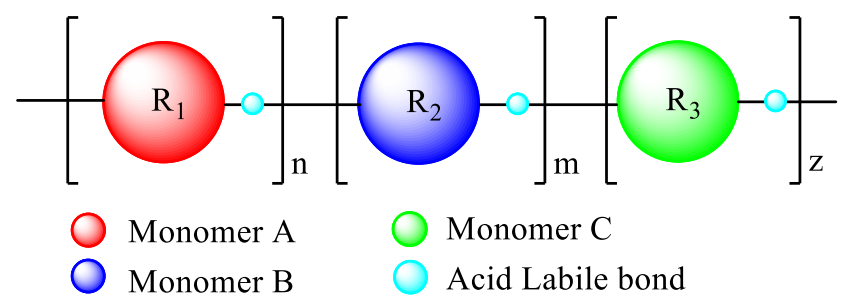

Figure 1: Chemical structure of the random copolymer. The monomers are connected with an acid-labile bond. Monomer R1 and R2 give properties such as glass transition temperature control, improved surface adhesion, solubility, etch resistance, and compatibility with other substances. Monomer R3 improves the compatibility between the random copolymer, the photoacid generator and the base quencher.

The molecular weights of the random copolymer were measured by GPC. The measured molecular weight is about $10 \mathrm{kDa}$ $\left(\mathrm{M}_{\mathrm{n}}\right)$ with polydispersity of about 1.7 . We note that this molecular weight is not very high but suitable for a resist material. To estimate the stability of the resist pattern, the $\mathrm{Tg}$ of the random copolymer was measured and was determined as $85{ }^{\circ} \mathrm{C}$. This is an acceptable Tg value for a resist candidate, since it is not so high to need extend PEB and it is not so low to induce pattern collapse after the development. The decomposition temperature as it is estimated by TGA was found as $190{ }^{\circ} \mathrm{C}$. The synthesized random copolymer demonstrated high thermal stability, and was considered as capable for highperformance photolithography applications.

\subsection{Imaging chemistry}

The acid labile bonds can be cleaved by the protons generated by the photoacid generators. When the proton generation takes place upon the irradiation, the acid-labile bond is cleaved, leading to the production of small hydrophilic products which are removed by the developer. To investigate the acidolysis activity, the film of the random copolymer containing $3 \%$ of TPS-Tf and $0.15 \%$ aminoanthracene as base quencher was exposed to low-pressure $\mathrm{Hg}$ light (254 nm) with the exposure dose of about $20 \mathrm{~mJ} / \mathrm{cm}^{2}$ and then baked at $80{ }^{\circ} \mathrm{C}$ for 2 minutes. 


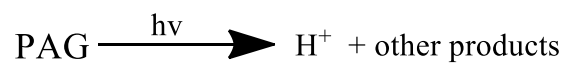

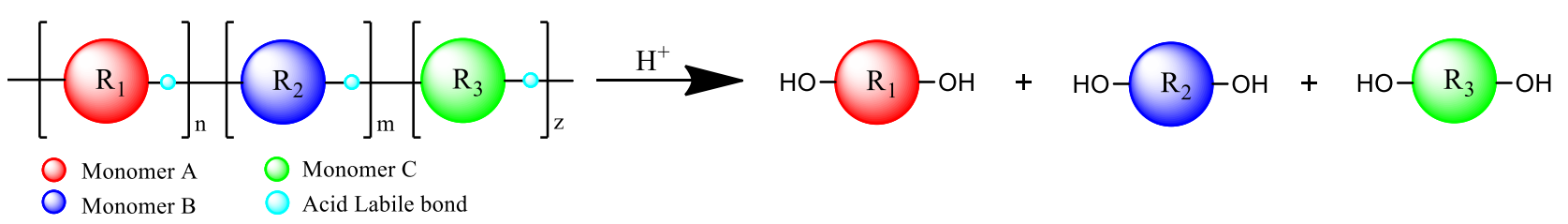

Figure 2: Main chain scission mechanism of the random copolymer after the influence of the photogenerated acid. The acid catalyzed backbone scission results in the production of low molecular weight hydroxyl molecules.

Figure 3 shows IR spectra of the random copolymer films with 5\% TPS-Tf photoacid generator with respect to polymer weight and 5\% aminoanthracene with respect to PAG weight. Line 1 corresponds to the random copolymer film after the post-application bake (PAB) for 5 minutes at $100{ }^{\circ} \mathrm{C}$, whereas the line 2 spectrum was taken after the exposure of the film at a dose of $20 \mathrm{~mJ} / \mathrm{cm}^{2}$ with $254 \mathrm{~nm}$ light. Line 1 and line 2 do not display significant differences indicating that the main chain scission is not affected by the generation of the acid after the irradiation. After the PEB (line 3 ) at $80{ }^{\circ} \mathrm{C}$ for 2 minutes, a new peak at $3100-3600 \mathrm{~cm}^{-1}$ is created suggesting the production of hydroxyl moieties during the cleavage of the polymer. This observation indicates that an acidolysis reaction takes place during the PEB step resulting in the desired solubility switch between the exposed and the unexposed areas. These findings suggest that the outgassing of the resist formulation during exposure is not significant, which is an important prerequisite of EUV resists to minimize the deposition of volatile resist molecules on the optics of the scanner.

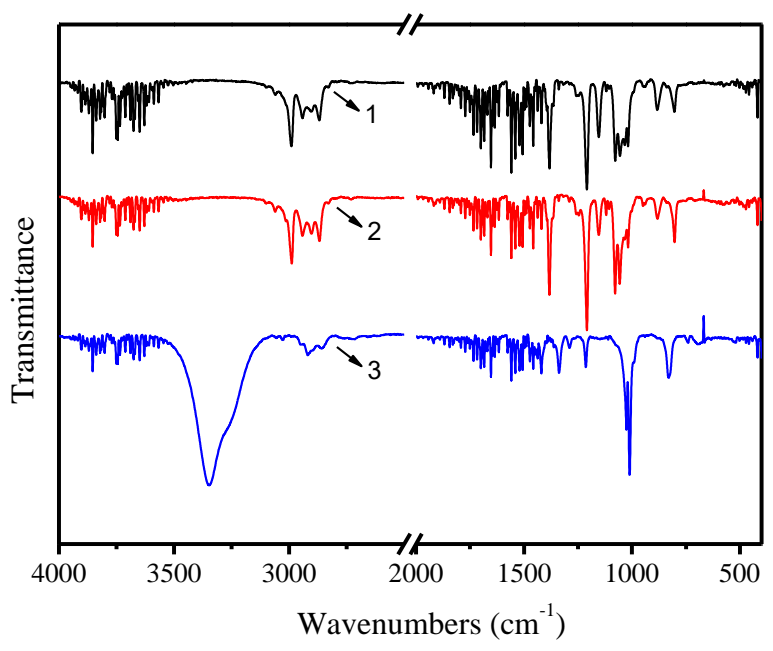

Figure 3: FT-IR spectra of random copolymer film containing 5\% TPS-Tf and 5\% aminoanthracene. Line 1 corresponds to the film after the $\mathrm{PAB}$ at $100^{\circ} \mathrm{C}$ for 5 minutes, 2: after the irradiation with $254 \mathrm{~nm}$ light and 3: after the PEB at $80{ }^{\circ} \mathrm{C}$ for 2 minutes.

\subsection{Lithographic and etch resistance properties}

Random copolymer thin films containing 5\% of TPS-Tf photoacid generator with respect to polymer weight and 5\% aminoanthracene with respect to PAG weight were created by spin-coating and following soft bake for $5 \mathrm{~min}$ at $100{ }^{\circ} \mathrm{C}$ to remove the remaining PGMEA solvent. Then, the films were exposed with EUV with an open frame at several radiation doses. After the exposure and PEB at $60{ }^{\circ} \mathrm{C}$ for 2 minutes, they were developed in tetramethylammonium hydroxide solution $(0.26 \mathrm{~N})$. The contrast curve obtained is shown in Figure 4. Under these conditions, the necessary exposure dose is less than $0.5 \mathrm{~mJ} / \mathrm{cm}^{2}$. It is obvious that this resist shows very high sensitivity with very good contrast. 


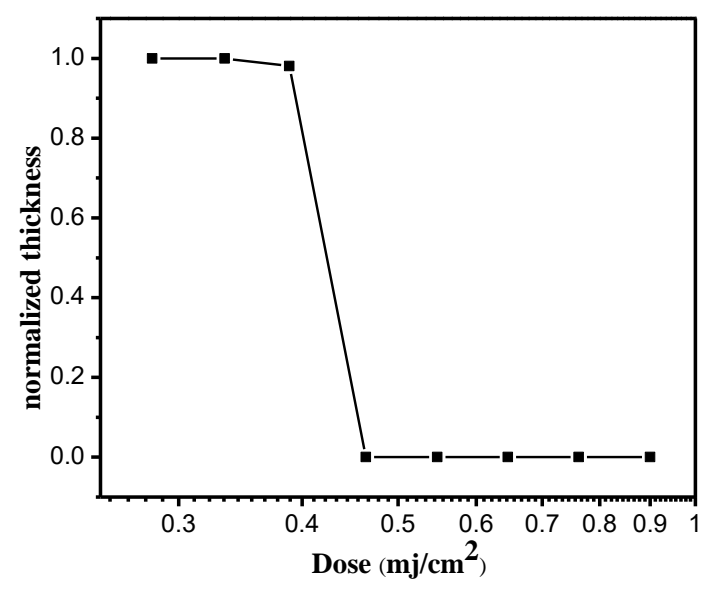

Figure 4: Contrast curve for the random copolymer photoresist system.

The etch rates measured in oxygen plasma for polymethyl methacrylate, AZ commercial novolac photoresist and our random copolymer based films are presented in Figure 5. The pressure of the oxygen gas was $10 \mathrm{mTorr}$ in $400 \mathrm{~W}$ power; these etch conditions are typical for an oxygen RIE process. The etch rate of the random copolymer (RCP) based film is distinctly better than Polymethyl methacrylate and it is comparable with a commercial novolac photoresist (AZ3214). The performance of the films in $\mathrm{He} / \mathrm{H}_{2} / \mathrm{C}_{4} \mathrm{~F}_{8}$ plasma is also shown, where a $\sim 1 / 10$ selectivity to $\mathrm{SiO}_{2}$ is demonstrated.

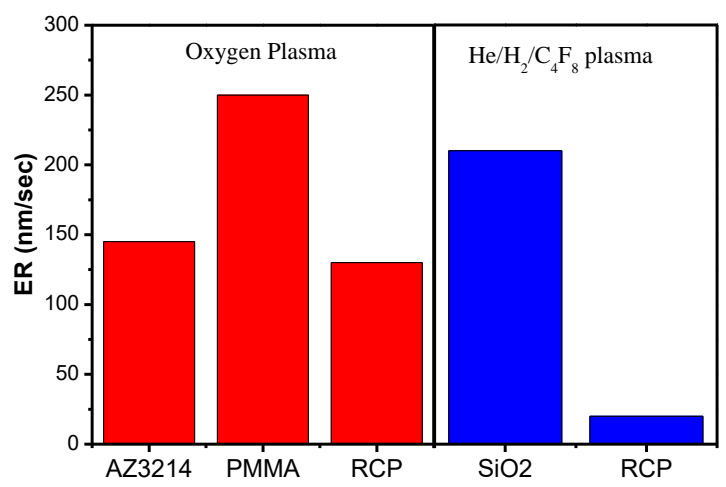

Figure 5: Etch resistance of the backbone breakable random copolymer (RCP) photoresist system.

\subsection{Lithographic evaluation}

Processing of the photoresist for the lithographic performance was carried out with the following steps. The resist formulations were spin-coated at $2000 \mathrm{rpm}$ for 1 minute to obtain $30 \mathrm{~nm}$ resist film thicknesses. The PAB of the resist was performed at $100{ }^{\circ} \mathrm{C}$ for 2 minutes following by exposure at EUV XIL-II beamline of the SLS synchrotron through a mask. After the exposure, a PEB was carried out at $60{ }^{\circ} \mathrm{C}$ for 2 minutes, followed by development using $0.26 \mathrm{~N}$ Tetramethylammonium hydroxide solution (TMAH) for 1 minute. Finally, the resists were rinsed with water and dried under $\mathrm{N}_{2}$ flow.

The resist formulations used contained in the table below (table 1):

Table 1: Resist formulations used in the EUV exposures. 


\begin{tabular}{|c|c|c|}
\hline Resist formulation & $\begin{array}{c}\text { PAG \% with respect to polymer } \\
\text { weight }\end{array}$ & $\begin{array}{c}\text { Base quencher \% with respect to } \\
\text { PAG weight }\end{array}$ \\
\hline 1 & 4 & 5 \\
\hline 2 & 4 & 10 \\
\hline 3 & 4 & 15 \\
\hline 4 & 5 & 5 \\
\hline 5 & 5 & 10 \\
\hline 6 & 5 & 15 \\
\hline 7 & 6 & 5 \\
\hline 8 & 6 & 10 \\
\hline 9 & 6 & 15 \\
\hline 10 & 7 & 5 \\
\hline 11 & 7 & 10 \\
\hline 12 & 7 & 15 \\
\hline
\end{tabular}

The aforementioned resist formulations were exposed at EUV through a mask for the fabrication $25 \mathrm{~nm}, 22 \mathrm{~nm}, 18 \mathrm{~nm}$, and $16 \mathrm{~nm}$ HP. 25 and $22 \mathrm{~nm}$ HP patterns were successfully resolved in the resist films; however, $18 \mathrm{~nm}$ and $16 \mathrm{~nm}$ HPs were not be resolved. In Figure 7, the SEM images for all formulations are presented.

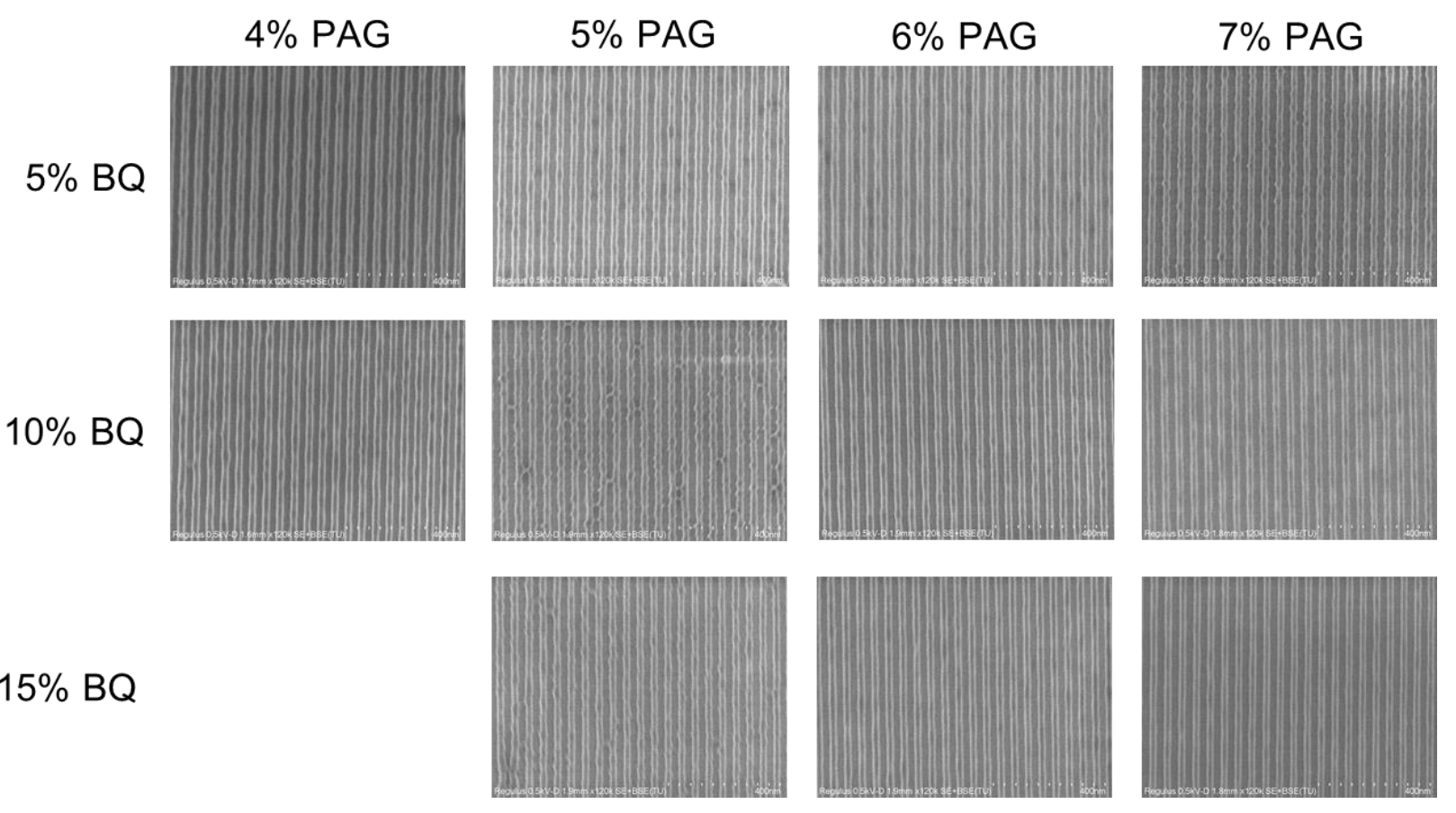

Figure 6: SEM images of the $25 \mathrm{~nm}$ half-pitch for the evaluated formulations.

Figure 7 shows the plots of LWR as a function of the dose-to-size for the $25 \mathrm{~nm}$ HP for different resist formulations. The process conditions were the same for all the exposures. The red line corresponds to 4\% PAG loading, the green line to 5\% PAG loading, the blue line to 6\% PAG loading and the magenta line to 7\% PAG loading whereas the rhombus symbol denotes $5 \%$ BQ loading, triangle symbol denotes $10 \%$ BQ and the circle symbol denotes $15 \% \mathrm{BQ}$. 


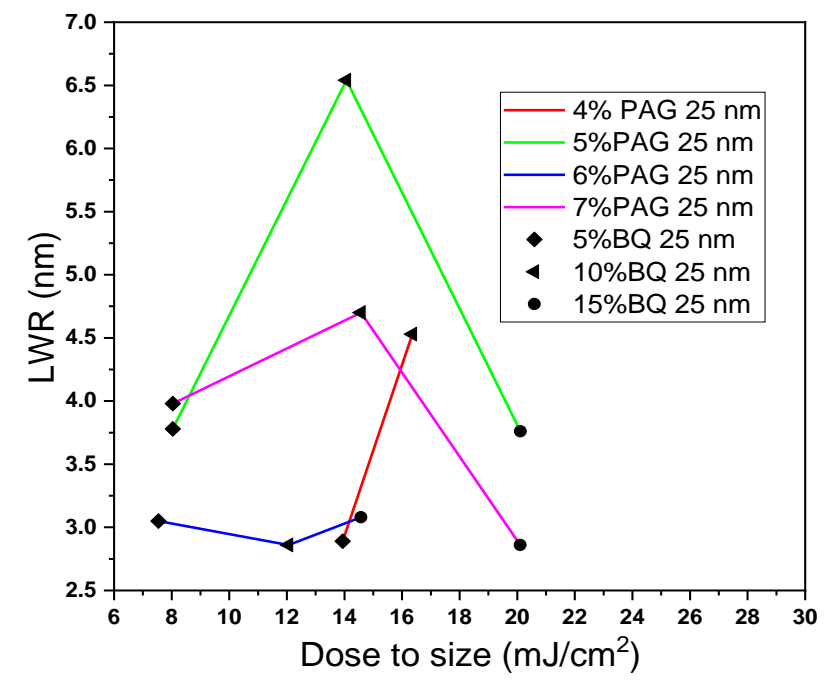

Figure 7: Line width roughness vs dose to size for $25 \mathrm{~nm} \mathrm{hp}$.

The data presented in Figure 7 suggests that the formulation with the higher PAG loading (7\%) and with the higher BQ loading (5\%) results in the lower LWR with $\sim 20 \mathrm{~mJ} / \mathrm{cm}^{2}$ dose to size. Comparable results were obtained using the lower PAG loading (4\%) and the lower BQ loading (5\%). Furthermore, the formulations with PAG loadings 5, 6 and $7 \%$ and $5 \%$ BQ need comparable dose to size $\sim 8 \mathrm{~mJ} / \mathrm{cm}^{2}$. Moreover, for the formulations with PAG loading 4, 5 and $7 \%, 10 \%$ BQ loading increases the LWR compared to 5 and 15\% BQ loadings. Only in the case of 6\% PAG and 10\% BQ loading the LWR is better than the $5 \%$ and $15 \%$ BQ loadings.

Figure 8 contains the SEM images from the evaluated formulations. It is clear that the patterns fabricated from the resist formulation consisting of 7\% PAG and 15\% BQ have the lower LWR.

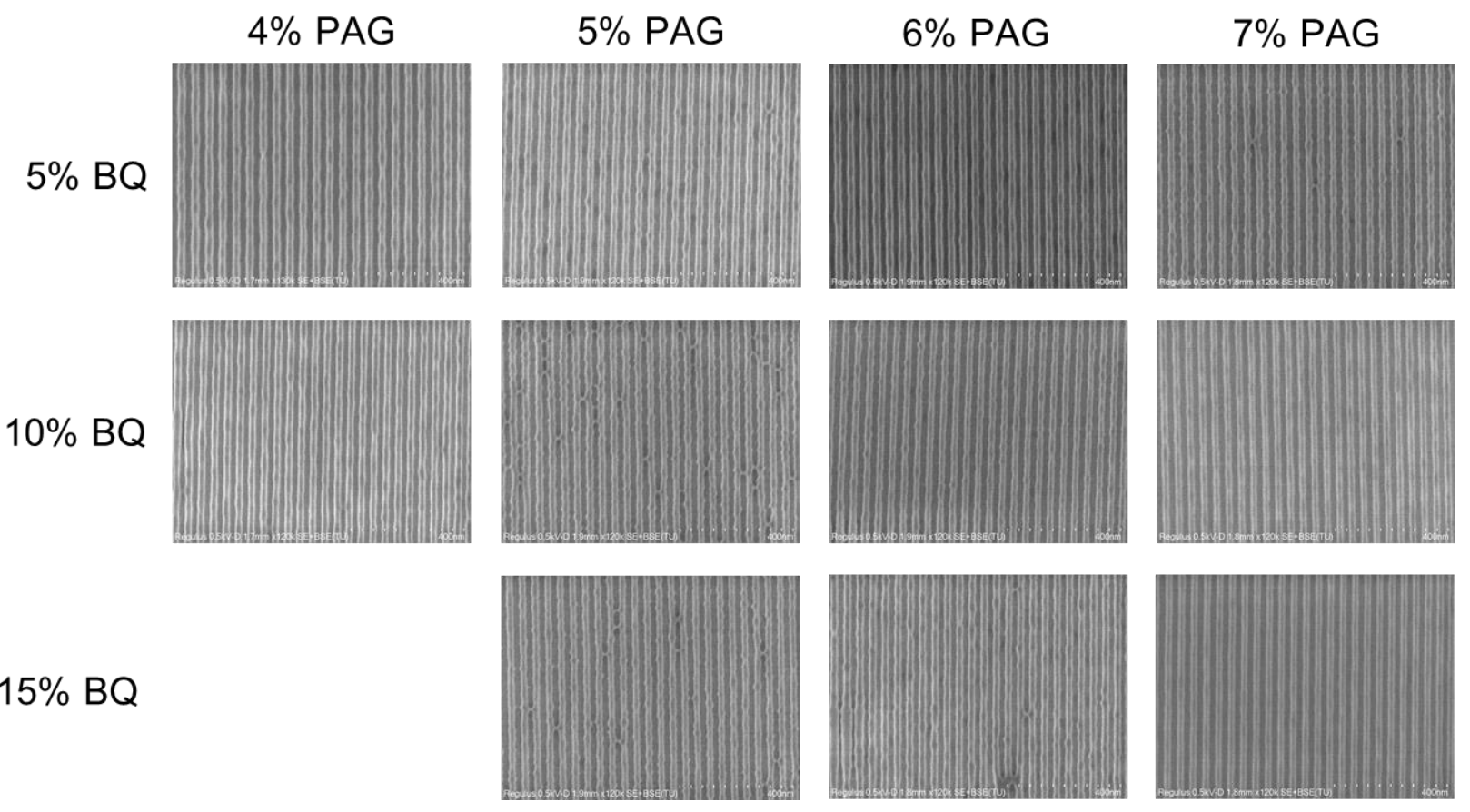

Figure 8: SEM images of the $22 \mathrm{~nm} \mathrm{HP}$ for the formulations evaluated in this study. 
Figure 9 shows the LWR versus dose to clear data for $22 \mathrm{~nm}$ HP. It is clear that the best results were obtained from the formulation consisted of 7\% PAG and $15 \% \mathrm{BQ}$. In this case, the LWR is $\sim 2.5 \mathrm{~nm}$ and the dose to clear is $\sim 19 \mathrm{~mJ} / \mathrm{cm}^{2}$. Furthermore, we observed a similar trend with the $25 \mathrm{~nm}$ HP concerning the intermediated BQ loading (10\%) which deteriorates the performance of the resist increasing the LWR compared to 5\% and 15\% BQ. In addition, for 5\%, 6\% and $7 \%$ PAG with 5\% BQ, the resist needs similar dose to clear, suggesting that the same amount of acid was produced during the exposure despite the different PAG amount in each formulation. The best results in the material's performance were obtained using $7 \%$ PAG loading and 15\% BQ loading.

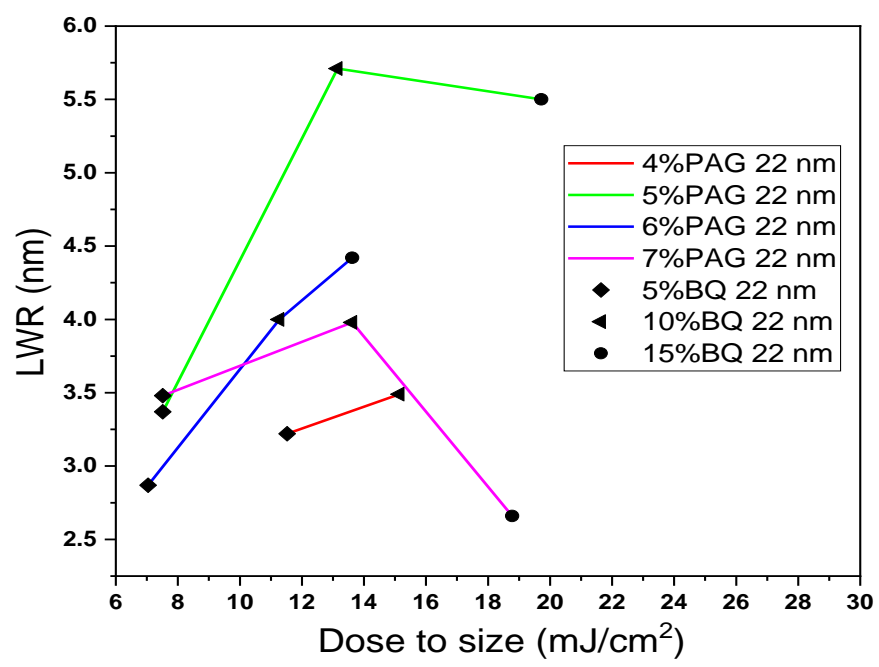

Figure 9: Line width roughness vs .dose-to-size for $22 \mathrm{~nm} \mathrm{HP}$.

\section{CONCLUSION}

A random backbone-scission copolymer containing several PAG/BQ ratios was evaluated at EUV. The resist can resolve $25 \mathrm{~nm}$ and $22 \mathrm{~nm}$ HPs. We investigated the impact of the ratio of the PAG/BQ on the performance of the material. Line width roughness versus dose-to-size plots was fabricated using different PAG and base quencher loadings. With the increasing amount of the base quencher, the resist needs more energy to be resolved. In some cases, the more BQ deteriorates the performance of the material, whereas there are some formulations with high BQ loading (15\%) in which the LWR retained in low values. The best-performance results in terms of LWR were achieved for $25 \mathrm{~nm}$ and $22 \mathrm{~nm}$ HP using 7\% PAG and 15\% BQ using $~ 18 \mathrm{~mJ} / \mathrm{cm}^{2}$ dose to size. Unfortunately, $18 \mathrm{~nm}$ and $16 \mathrm{~nm}$ half pitches were not resolved. Future work will include the optimization of the random copolymer using more bulky monomers in order to increase the stiffness of the resist. Furthermore, a suitable underlayer will be synthesized to increase the adhesion of the polymer with the substrate.

\section{ACKNOWLEDGMENTS}

The authors would like to thank Michaela Vockenhuber for her assistance with the EUV exposures.

\section{REFERENCES}

[1] T. Manouras, and P. Argitis, "High Sensitivity Resists for EUV Lithography: A Review of Material Design Strategies and Performance Results," Nanomaterials, 10(8), 1593 (2020).

[2] R. Del Re, J. Passarelli, M. Sortland, B. Cardineau, Y. Ekinci, E. Buitrago, M. Neisser, D. Freedman, and R. Brainard, "Low-line edge roughness extreme ultraviolet photoresists of organotin carboxylates," Micro Nanolithogr MEMS MOEMS, 14(4), 043506 (2015). 
[3] C. Luo, C. Xu, L. Lv, H. Li, X. Huang, and W. Liu, "Review of recent advances in inorganic photoresists," RSC Adv., 10(14), 8385-8395 (2020).

[4] D. De Simone, P. Vanelderen, and G. Vandenberghe, "Photo Material Readiness at the Eve of EUVL HVM," J Photopolym Sci Tec, 30(5), 613-617 (2017).

[5] J. Jiang, D. De Simone, and G. Vandenberghe, "Metal Sensitizer in Chemically Amplified EUV Resist: a Study of Sensitivity Enhancement and Dissolution," J Photopolym Sci Tec, 30(5), 591-597 (2017).

[6] O. R. Wood Ii, "EUVL: Challenges to Manufacturing Insertion," J Photopolym Sci Tec, 30(5), 599-604 (2017).

[7] S. Nagahara, C. Q. Dinh, K. Yoshida, G. Shiraishi, Y. Kondo, K. Yoshihara, K. Nafus, J. Petersen, D. De Simone, P. Foubert, G. Vandenberghe, H.-J. Stock, and B. Meliorisz, "EUV resist chemical gradient enhancement by UV flood exposure for improvement in EUV resist resolution, process control, roughness, sensitivity, and stochastic defectivity," Proc. SPIE 11326, 113260A (2020).

[8] S. Nagahara, M. Carcasi, G. Shiraishi, Y. Kamei, K. Nafus, Y. Minekawa, H. Ide, Y. Kondo, T. Shiozawa, K. Yoshida, M. Enomoto, K. Yoshihara, H. Nakashima, S. Biesemans, R. Shimada, M. Tomono, K. Takeshita, T. Moriya, H. Makoto, R. Aizawa, Y. Konishi, M. Hori, K. Maruyama, H. Nakagawa, M. Miyake, T. Nagai, S. Dei, T. Naruoka, M. Shima, T. Kimura, G. Vandenberghe, J. Petersen, D. De Simone, F. Philippe, H.-J. Stock, B. Meliorisz, A. Oshima, and S. Tagawa, "EUV resist sensitization and roughness improvement by PSCAR with inline UV flood exposure system," Proc. SPIE 10586, 1058606 (2018).

[9] S. A. Kruger, C. Higgins, B. Cardineau, T. R. Younkin, and R. L. Brainard, "Catalytic and Autocatalytic Mechanisms of Acid Amplifiers for Use in EUV Photoresists," Chem. Mater., 22(19), 5609-5616 (2010).

[10] R. Brainard, S. Kruger, C. Higgins, S. Revuru, S. Gibbons, D. Freedman, W. Yueh, and T. Younkin, "Kinetics, Chemical Modeling and Lithography of Novel Acid Amplifiers for Use in EUV Photoresists," J Photopolym Sci Technol, 22(1), 43-50 (2009).

[11] G. O'Callaghan, C. Popescu, A. McClelland, D. Kazazis, J. Roth, W. Theis, Y. Ekinci, and A. P. Robinson, "Multitrigger resist: novel synthesis improvements for high resolution EUV lithography," Proc. SPIE 10960, 109600C (2019).

[12] C. Popescu, A. Frommhold, A. McClelland, J. Roth, Y. Ekinci, and A. P. Robinson, "Sensitivity enhancement of the high-resolution xMT multi-trigger resist for EUV lithography," Proc. SPIE 10143, 101430V (2017).

[13] C. Popescu, D. Kazazis, A. McClelland, G. Dawson, J. Roth, W. Theis, Y. Ekinci, and A. P. Robinson, "Highresolution EUV lithography using a multi-trigger resist," Proc. SPIE 10583, 105831L (2018).

[14] C. Popescu, Y. Vesters, A. McClelland, D. De Simone, G. Dawson, J. Roth, W. Theis, G. Vandenberghe, and A. P. G. Robinson, "Multi Trigger Resist for EUV Lithography," J Photopolym Sci Technol, 31(2), 227-232 (2018).

[15] D. R. S. Cumming, S. Thoms, J. M. R. Weaver, and S. P. Beaumont, "3 nm NiCr wires made using electron beam lithography and PMMA resist," Microelectron. Eng., 30(1-4), 423-425 (1996).

[16] W. C. Hu, K. Sarveswaran, M. Lieberman, and G. H. Bernstein, "Sub-10 nm electron beam lithography using cold development of poly(methylmethacrylate)," J. Vac. Sci. Technol. B, 22(4), 1711-1716 (2004).

[17] T. Manouras, D. Kazazis, E. Koufakis, Y. Ekinci, M. Vamvakaki, and P. Argitis, "Ultra-sensitive EUV resists based on acid-catalyzed polymer backbone breaking," Proc. SPIE 10583, 105831R (2018).

[18] N. Mojarad, D. Fan, J. Gobrecht, and Y. Ekinci, "Broadband interference lithography at extreme ultraviolet and soft x-ray wavelengths," Opt. Lett., 39(8), 2286-2289 (2014). 